\title{
A INTERDEPENDÊNCIA DAS ESFERAS DA REPRODUÇÃO E PRODUÇÃO NA PRODUÇÃO DE INDICADORES: REFLEXÕES A PARTIR DA EXPERIÊNCIA DAS MULHERES RURAIS NO SERTÃO DO APODI
}

\author{
Maria da Conceição Dantas Moura ${ }^{1}$ e \\ Renata Faleiros Camargo Moreno ${ }^{2}$
}

\begin{abstract}
RESUMO
0 artigo tem como objetivo refletir sobre a interdependência das esferas produtiva e reprodutiva, a partir de elaborações feministas que buscam conferir visibilidade ao trabalho doméstico e de cuidados nas estatísticas e indicadores sociais. Situando esta discussão na realidade brasileira, notadamente na experiência das mulheres rurais, o artigo apresenta uma análise inicial de dados referentes à realidade de 160 mulheres do Sertão do Apodi, colhidos em diagnóstico realizado entre março e maio de 2011. A análise se referencia nos conceitos da economia feminista e recupera iniciativas governamentais, da sociedade civil e do meio acadêmico no que se refere ao levantamento de dados sobre trabalho das mulheres na esfera produtiva e reprodutiva.
\end{abstract}

Palavras-chave: Economia feminista. Mulheres rurais. Trabalho doméstico. Cuidados.

\footnotetext{
Mestre em Ciências Sociais pela Universidade Federal do Rio Grande do Norte, Brasil. conceicaommm@gmail.com

2 Mestre em Ciências Humanas e Sociais pela Universidade Federal do ABC, Brasil. ticamoreno@gmail.com
} 


\title{
THE INTERDEPENDENCE OF THE PRODUCTION AND REPRODUCTION SPHERES IN THE PRODUCTION OF INDICATORS: REFLECTIONS FROM THE EXPERIENCE OF RURAL WOMEN IN SERTÃO DO APODI
}

\begin{abstract}
The article aims to reflect on the interdependence of the production and reproduction spheres from feminist elaborations that try to make care and housework visible in statistics and social indicators. Taking the Brazilian reality into consideration, especially the experience of rural women, the article presents an initial data analysis of the reality of 160 women from Sertão do Apodi, collected through diagnosis in the period between March and May, 2011.The analysis draws on the concepts of feminist economics and recovers initiatives taken by the government, civil society and academia regarding data collection on women's work in the productive and reproductive spheres.
\end{abstract}

Keywords: Feminist economics. Rural women. Housework. Care.

\section{INTRODUÇÃO}

A partir dos anos 1960, com o surgimento da segunda onda do feminismo, diversas áreas do conhecimento estiveram sujeitas à crítica metodológica e epistemológica elaborada pelo pensamento feminista. Esta crítica tem como um de seus elementos o questionamento ao androcentrismo, que se caracteriza pela construção de noções que tomam a experiência dos homens como universal, além de ocultar e, por vezes, desconsiderar a experiências das mulheres.

A evolução da perspectiva feminista é marcada pela interdisciplinaridade, sobretudo no que se refere à tentativa de explicar fenômenos sociais, na qual, com frequência, sociologia, história e economia convergem. A economia feminista acumulou em sua trajetória a necessidade de ampliação das fronteiras tradicionais da economia, definidas pelo sistema mercantil e monetário, e a recuperação do trabalho doméstico e de cuidados como parte fundamental dos processos de produção e reprodução da vida. Paralelamente, os acúmulos dos estudos sobre divisão sexual do trabalho na sociologia avançaram no mesmo sentido ao demonstrar a interdependência entre os chamados trabalhos reprodutivo e produtivo.

De acordo com Kergoat (2009), a forma de divisão do trabalho decorrente das relações sociais de sexo (a divisão sexual do trabalho) se caracteriza pela destinação prioritária dos homens à esfera produtiva e das mulheres à esfera reprodutiva, atribuindo, simultaneamente, forte valor social agregado às funções ocupadas por 
homens. Separação e hierarquização são os dois princípios organizadores da divisão sexual do trabalho.

A divisão sexual do trabalho e a interdependência entre as esferas da reprodução e produção são as noções orientadoras deste artigo, que pretende contribuir para a reflexão sobre a construção de análises e indicadores capazes de avaliar as configurações da desigualdade de gênero de modo a orientar a elaboração de políticas geradoras de igualdade. A partir da recuperação dos debates feministas sobre a construção de estatísticas e indicadores, apresentamos aqui uma análise inicial de dados relativos ao trabalho das mulheres na região da região Oeste do Rio Grande do Norte, especificamente do território Sertão do Apodi ${ }^{3}$ O Sertão do Apodi é uma região semiárida que é referência nacional na produção agroecológica e de convivência com o semiárido, sendo responsável pela segunda maior produção de mel de abelha do Brasil e uma das maiores produções de caprinocultura. É uma realidade pesquisada pela academia por seu potencial social e produtivo, pela produção agroecológica e pela concentração de uma diversidade de experiências com grupos produtivos de mulheres.

Os temas que movem a organização das trabalhadoras rurais da região são, principalmente, a economia feminista e solidária, entrelaçada a conquistas reais na vida das mulheres, como, por exemplo, o acesso às políticas locais e sua inserção na produção, apoio à produção e reprodução, crédito e agroecologia (ALVES, 2007). 0 processo de organização das mulheres rurais da região se intensificou nos últimos dez anos com a mobilização de mulheres para acessar políticas públicas.

Entendendo a ruralidade não apenas como espaço social da produção agrícola, mas também como representação, ou seja, um objeto construído pela prática dos atores sociais e políticos, o Sertão do Apodi é caracterizado como um rural pautado pela agricultura familiar, organização social e acesso às políticas públicas.

\section{UMA APROXIMAÇÃO ÀS PESQUISAS SOBRE TEMPO E TRABALHO DAS MULHERES NO BRASIL}

No Brasil, inicialmente centrados no trabalho remunerado realizado na esfera da produção e no mercado de trabalho, os estudos sobre o trabalho das mulheres passaram a incorporar um olhar sobre o trabalho realizado na esfera da reprodução social e, posteriormente, sobre a articulação entre as duas esferas (BRUSCHINI, 2006).

Nos anos 1970 e 1980, foi desenvolvido um debate sobre a insuficiência das estatísticas existentes, demonstrando seus limites para medir o conjunto da atividade

\footnotetext{
${ }^{3}$ Com a estruturação do programa do governo Federal Territórios da Cidadania, em 2004, a região Oeste do Rio Grande do Norte foi dividida em dois territórios: Açu-Mossoró e Sertão do Apodi.
} 
econômica das mulheres. Isto porque, em parte, as categorias utilizadas eram inspiradas nas propostas dos organismos internacionais, elaboradas a partir do referencial dos países desenvolvidos.

Enfatizavam a produção industrial, ocultando o contexto doméstico - a pequena produção mercantil, o trabalho voltado ao autoconsumo e o trabalho a domicílio, particularmente relevantes para se medir a atividade econômica das mulheres, especialmente das mulheres rurais. A classificação de atividade ou inatividade econômica esteve e segue no centro dos debates sobre a produção de estatísticas, tanto a partir do Censo do IBGE como da Pesquisa Nacional por Amostra de Domicílios (PNAD).

0 processo de críticas e reformulações das formas de medição do tempo destinado ao trabalho doméstico culminou, até 0 momento, em duas modificações no questionário utilizado na PNAD. Em 1992, foi introduzida a questão 121 no questionário, sobre se o/a entrevistado/a realizou afazeres domésticos ${ }^{4}$ na semana de referência. Nove anos mais tarde, foi introduzida uma segunda questão, sobre quantas horas foram dedicadas aos afazeres domésticos na semana de referência (BRUSCHINI, 2006, p. 335).

A medição das horas gastas com os afazeres domésticos contribui para dar visibilidade ao trabalho doméstico realizado principalmente pelas mulheres. Atualmente, a partir de iniciativa coordenada entre a Secretaria de Políticas para Mulheres (SPM) e o IBGE, está em processo de elaboração e debate uma pesquisa sobre os usos do tempo, que qualifica a medição do tempo e do trabalho, possibilitando maior compreensão sobre as configurações e dinâmicas estabelecidas com a interdependência da esfera da produção e reprodução.

A disponibilização dos dados sobre o tempo destinado aos afazeres domésticos constituiu um instrumento para as proposições de novas reformulações nas pesquisas, que estão em debate, para que os afazeres domésticos passem a ser considerados como trabalho doméstico não remunerado, e não mais como inatividade econômica (BRUSCHINI, 2006, p. 351).

A problematização feita por Dedecca (2004) sobre o tempo no capitalismo organiza este debate tanto do ponto de vista teórico como da elaboração de estatísticas e de políticas públicas. 0 autor trata da articulação entre o tempo da reprodução econômica e o tempo da reprodução social, afirmando que um não se processa sem 0 outro. Defende que se trate o tempo do chamado trabalho doméstico como tempo para reprodução social, entendendo este como "fundamental para resolver alguns problemas

\footnotetext{
${ }^{4}$ Os afazeres domésticos, conforme denominado na PNAD apreende parte da preocupação feminista com 0 trabalho doméstico não remunerado.
} 
da acumulação capitalista que não se equacionam no sistema generalizado de trocas realizadas através da moeda." (DEDECCA, 2004, p. 25).

A incorporação de questões como o trabalho doméstico não remunerado, tomadas como problemáticas a serem verificadas pelos institutos de pesquisa, formuladores e gestores de políticas públicas, relaciona-se com a evolução do debate teórico. Neste sentido, torna-se pertinente resgatar o debate da economia feminista na elaboração de estatísticas e indicadores.

\section{CONTRIBUIÇÕES DA ECONOMIA FEMINISTA PARA A ELABORAÇÃO DE INDICADORES}

A economia é uma ciência construída socialmente, portanto, as relações e conflitos que marcam a estrutura social influenciam na consideração da relevância das questões a serem estudadas (CARRASC0, 2003; FERBER; NELSON, 2004; PÉREZ, 2006). A perspectiva feminista introduziu uma crítica à exclusão das mulheres do objeto de estudo da teoria econômica ao apontar que, com a suposta neutralidade de suas categorias e conceitos, "a economia tem desenvolvido uma metodologia que não consegue "ver' o comportamento econômico das mulheres." (PUJOL, 1992 apud CARRASC0, 1999).

A trajetória desta corrente, desenvolvida especialmente nos Estados Unidos e Europa, é marcada pela elaboração de metodologias e análises não androcêntricas. Propõe que a compreensão sobre a situação das mulheres seja analisada a partir de sua própria experiência, e não apenas a partir do que lhes falta para se igualarem aos homens (CARRASCO, 2006). Esta elaboração desemboca na proposição de novos tipos de indicadores, capazes de superar o referencial masculino para a medição da qualidade de vida da sociedade, consolidando um novo arcabouço teórico. A economia feminista se apresenta como uma ferramenta para o desenvolvimento de políticas públicas sem 0 viés androcêntrico e, desta forma, construtoras da perspectiva da igualdade entre homens e mulheres como componente estruturante de um novo padrão de desenvolvimento.

0 que se pretende desde a economia feminista em sua crítica à macroeconomia e à concepção das políticas econômicas é desenvolver perspectivas que considerem as relações de gênero tanto na elaboração de estruturas conceituais e modelos formais como na pesquisa empírica estatística de países específicos, estudos comparativos entre eles ou em diagnósticos de problemas macroeconômicos e a formulação das correspondentes políticas para tentar dar-lhes solução (CATAGAY et al., 1995 apud CARRASC0, 1999, p. 35). 
Conferir visibilidade ao trabalho doméstico e de cuidados é uma questão central para a economia feminista, uma vez que a reprodução social depende desse trabalho realizado majoritariamente pelas mulheres. Ao ignorar isso, a análise econômica se realiza de forma enviesada, apresentando um diagnóstico incompleto do funcionamento do sistema econômico, além de se equivocar ao avaliar a repercussão real das políticas públicas. Além disso, a organização social do cuidado, seja entre homens e mulheres, seja entre Estado, família e mercado, explica boa parte das desigualdades existentes - de gênero e de classe, motivação de parte considerável das pesquisadoras que se dedicam a construir a economia feminista (RODRIGUEZ, 2012).

Os debates feministas sobre novas metodologias de análise e construção de indicadores tiveram entre seus resultados a elaboração de pesquisas de usos do tempo, índices desagregados e índices sintéticos de gêneros. De acordo com Teixeira (2012), a disseminação destes se deu ao longo dos anos 1990 e culminou na existência, atualmente, de oito índices sintéticos de gênero internacionais.

A elaboração feminista sobre indicadores com base no gênero tem apontado que, além de contribuir para dar visibilidade ao trabalho doméstico e de cuidados realizado na esfera da reprodução como aquele que contribui para melhorar as condições de saúde e educação, por exemplo, esta deveria ser analisada com a consideração das consequências geradas pela sobrecarga de trabalho das mulheres em diversos âmbitos. De acordo com Folbre (2011) se as mulheres temem que um emprego em tempo integral afete o bem estar dos filhos, vão buscar empregos em tempo parcial e com mais flexibilidade - informalidade e precarização, características do mercado de trabalho feminino.

0 cuidado impõe custos, em forma de obrigações financeiras, oportunidades perdidas e salários aos que se renuncia, mas também gera compensações intrínsecas, vínculos familiares e sociais mais sólidos e serviços de alta qualidade para as pessoas dependentes (FOLBRE, 2011, p. 279).

Sem indicadores capazes de dar visibilidade e medir as atividades no âmbito doméstico, marcado pela desigualdade, a construção de igualdade não irá figurar entre os objetivos da política pública. Folbre (2011) ressalta o fato de que o aumento da participação feminina no mercado de trabalho remunerado não foi acompanhado por uma reorganização do trabalho de cuidados. Isto pode implicar, de acordo com 0 contexto, a "feminização da pobreza" ou a "pauperização da maternidade".

Pérez (2006) aponta que a centralidade do mercado na teoria econômica e a exclusão da esfera da reprodução e do trabalho doméstico e de cuidados não remunerado são expressas no Sistema de Contas Nacionais (SCN), a partir do qual se conhece, compara e analisa a realidade econômica dos países. Toda atividade que não é 
contabilizada nesses sistemas, desenvolvidos com métodos semelhantes, desaparece da análise econômica, e, logo, da realidade (CARRASC0, 2012). A crítica à metodologia dos Sistemas de Contas Nacionais é uma das áreas com maior concentração de estudos da economia feminista, na qual se travam grandes debates sobre o que e como deve ser medido, especialmente no que se refere ao trabalho doméstico e de cuidados. Até 1993, o SCN excluía muitos aspectos da produção de subsistência assumidos pelas mulheres, como buscar água, lenha ou a produção de alimentos para o autoconsumo. Os questionamentos e propostas feministas tiveram influência na incorporação destas atividades, mas ainda tem muito para avançar.

As feministas apresentam certa desconfiança com a utilização exclusiva de métodos quantitativos. Teixeira (2012) afirma que a produção feminista de indicadores aposta em pesquisas quantitativas e qualitativas, que buscam pesquisas de profundidade, entrevistas, grupo focal, entre outros. Da mesma forma, Corner (2002 apud FOLBRE, 2011), afirma que muitas vezes uma etnografia é importante para matizar alguns elementos que aparecem nas pesquisas quantitativas.

Há pesquisas e estudos da economia feminista que demonstram estar em um estágio avançado de proposição de novas metodologias e indicadores não androcêntricos. 0 estudo realizado por Cristina Carrasco, na Espanha, sobre a Pesquisa de População Ativa (EPA, na sigla em espanhol), ilustra este processo.

Carrasco (2008) apresenta proposições referentes ao que deve ser o ponto de partida da economia que incorpora a experiência feminina como parte de sua análise geral e não como um capítulo à parte. A autora propõe a EPA-NA (não androcêntrica), na qual o debate teórico sobre o que deve ser considerado e medido é central. Isso porque as estatísticas sobre o trabalho se estruturam de forma a analisar de maneira separada 0 que é o emprego e o que é o trabalho familiar doméstico, ou seja, sem estabelecer os vínculos entre os dois, desconsiderando o trabalho que é realizado em sua grande parte pelas mulheres, de forma não remunerada, no interior dos lares. Outro aspecto refere-se à consideração de trabalho apenas desde o emprego, fato que embasa as pesquisas sobre a população economicamente ativa em várias partes do mundo.

Para incorporar as mulheres é necessário reconceituar a categoria trabalho. Para isso, a proposta da EPA-NA estabelece a relação entre o trabalho doméstico e de cuidados não remunerado e o trabalho remunerado das pessoas, e inclui uma dimensão fundamental que é a análise dos tempos da produção e da reprodução, e como eles se determinam mutuamente. A EPA-NA parte da ideia de que o lar é o espaço desde o qual se organiza a vida e, portanto, pretende ser um marco de análise adequado para captar a atividade das pessoas em toda sua profundidade. Isso significa, segundo Carrasco (2008, p. 231), "deslocar o núcleo analítico desde o mercado às pessoas, e desde as necessidades de produção às necessidades humanas." 
A noção de que a esfera da produção é independente da esfera da reprodução se baseia em uma dicotomia que constrói o imaginário social de que as pessoas nascem prontas para o mercado e são independentes. Como afirma Nobre (2002), no imaginário produzido pela economia clássica e neoclássica é como se os indivíduos não tivessem sido crianças e não ficassem velhos, portanto, não precisariam de cuidados. É como se as pessoas chegassem à idade adulta sem a necessidade dos trabalhos da "produção do viver". Esta falsa autonomia oculta 0 trabalho da reprodução, realizado majoritariamente pelas mulheres. É pertinente a afirmação de Carrasco (2003) quando diz que o mercado prevê quando a pessoa tem ou deve ter o seu tempo disponibilizado para a produção. Paradoxalmente, a reprodução constrói a lógica do cuidado que exige acompanhamento dos ciclos da vida, desde a infância até a velhice.

\section{ECONOMIA FEMINISTA: ASPECTOS DA EXPERIÊNCIA BRASILEIRA}

No Brasil, esse debate ocorre em diversas frentes. A SOF (Sempreviva Organização Feminista), desde o início dos anos 2000, tem feito um esforço para reunir pesquisadoras e articular grupos de estudos visando a apropriação da economia feminista a partir da realidade brasileira, tendo como referência a interdependência das esferas produtiva e reprodutiva. São exemplos deste processo a constituição da REF (Rede Economia e Feminismo) e a realização do Seminário Internacional "Trabalho Doméstico e de Cuidados - Por outro paradigma de sustentabilidade da vida humana", em 2006, quando foi apresentada a proposta de indicadores não androcêntricos, elaborada por Cristina Carrasco.

Esforços dessa natureza têm influenciado pesquisadores/as, órgãos governamentais e sociedade civil. No entanto, ainda persistem as dificuldades de elaboração de indicadores capazes de incorporar a totalidade do trabalho das mulheres como parte constitutiva do desenvolvimento da sociedade. Pesquisas recentes, no Brasil, analisam dados produzidos pelos institutos de pesquisa ou instituições acadêmicas buscando visibilizar e reunir as informações disponíveis sobre a temática do cuidado (HIRATA; GUIMARÃES, 2012).

Embora ainda sejam poucos os estudos nessa área que consideram as mulheres rurais, é possível verificar avanços no que se refere a esse debate. Em 2009, o IBGE divulgou as informações do Censo Agropecuário de 2006. Em conformidade com 0 Censo Agropecuário Mundial, o Censo apresentou duas importantes informações desagregadas por sexo. A primeira delas é a identificação por sexo do responsável pelo estabelecimento produtivo. No entanto, quando se considera quem dirige tal estabelecimento, apenas um dos produtores é considerado. Por se tratar de uma sociedade estruturada por relações desiguais de gênero, na que a figura masculina permanece legitimada como representante legal da agricultura familiar, na maioria dos 
estabelecimentos foi o homem, e não a mulher, o produtor considerado. 0 censo também desagrega por sexo as informações sobre pessoal ocupado. No entanto, ainda persiste o limite de não se considerar atividades importantes como a criação nos quintais como produtivas, o que demonstra que os estudos feitos a partir destes dados ainda tem dificuldade de medir em suas análises a totalidade do trabalho das mulheres, compreendido pelas atividades na esfera da reprodução e da produção.

Do ponto de vista governamental, vale ressaltar o conjunto de iniciativas da Diretoria de Políticas para as Mulheres Rurais do Ministério do Desenvolvimento Agrário (MDA). São exemplos a edição e publicação de Estatísticas Rurais e a Economia Feminista (BUTT0, 2009) e Mulheres nas estatísticas Agropecuárias- Experiências em países do Sul (BUTTO, DANTAS; HORA, 2012) com estudos de dados dos países pertencentes ao Mercosul.

Considerando esse contexto nacional de iniciativas de elaboração e análises de indicadores a partir de uma perspectiva feminista, o Centro Feminista 8 de Março (CF8), organização feminista sediada em Mossoró, Rio Grande do Norte, desenvolve suas experiências de assessoria à organização produtiva das mulheres, tendo como referência o debate da economia feminista. 0 CF8 elaborou um diagnóstico para a realização de um de seus programas, o ATER-Mulheres (Assistência Técnica de Extensão Rural) executado em parceria com o Ministério do Desenvolvimento Agrário. 0 diagnóstico contém dados que, ainda que iniciais, permitem perceber a realidade do trabalho das mulheres a partir da ampliação deste conceito. Ou seja, os dados consideram não apenas o trabalho remunerado, mas também o não remunerado, o trabalho doméstico e de cuidados. A pertinência de análise destes dados reside na necessidade de multiplicar experiências de estudos com indicadores não androcêntricos no meio rural, considerando que esse debate tende a se expandir no meio acadêmico feminista. Além disso, este diagnóstico tem incidência concreta na vida das mulheres rurais, uma vez que orientam a atuação do ATER-Mulheres na região.

Os dados analisados neste artigo foram disponibilizados pelo CF8. 0 diagnóstico foi a primeira ação realizada pelo projeto ATER- Mulheres, entre março e maio de 2011, e teve como objetivo levantar as demandas de produção das mulheres para orientar a atuação da assistência técnica contratada pelo projeto. As questões do diagnóstico foram elaboradas em Brasília pela Diretoria de Políticas para as Mulheres, em conjunto com a equipe de acompanhamento dos contratos de Ater-Mulheres. 0 CF8 introduziu questões relacionadas ao acesso à água e à realização do trabalho doméstico considerando sua relação com a organização produtiva das mulheres.

A decisão de incluir no diagnóstico estas duas questões partiu da realidade local e da experiência de trabalho do CF8. A questão da água foi introduzida porque as mulheres que seriam beneficiárias moram em uma região semiárida e qualquer 
iniciativa de fortalecimento produtivo deveria partir da viabilidade hídrica. A outra questão, referente ao trabalho doméstico, foi introduzida após uma reflexão do CF8 sobre sua experiência em assessoria a outros grupos produtivos, em que se concluiu que um dos entraves para a ampliação da produção das mulheres poderia ser 0 grande número de horas dedicado às responsabilidades com o trabalho doméstico.

0 levantamento dos dados primários foi realizado através de questionário pela equipe técnica do CF8. 0 público alvo da pesquisa foram as mulheres rurais beneficiárias do contrato de ATER mulheres no território do Sertão do Apodi. As mulheres são agricultoras cadastradas na Declaração de Aptidão Profissional (DAP), documento expedido pela assistência técnica rural do estado e entidades representativas, como sindicatos dos trabalhadores rurais.

0 diagnóstico teve como objetivo conhecer as atividades produtivas e reprodutivas realizadas pelas mulheres, bem como as demandas de assistência técnica. 0 questionário foi composto por três blocos de questões: identificação das mulheres com perfil (idade, estado civil, raça/cor, identidade profissional); questões agrárias e agrícolas, envolvendo temas como produção, infraestrutura, acesso ao mercado e políticas públicas; questões sobre a reprodução, o trabalho doméstico e de cuidados e sobre 0 acesso a água.

0 diagnóstico foi aplicado em 11 municípios que conformam o território da cidadania Sertão do Apodi, totalizando 160 mulheres entrevistadas. Destas, 96,9\% se identificam como agricultoras, 2,5\% como quilombolas e $0,6 \%$ como pescadoras. Entre as entrevistadas, 87 se declaram negras e 70 brancas. Com relação ao estado civil, a maioria é casada (86) ou vive em união estável (52). Apenas 13 mulheres são solteiras, 6 viúvas e 3 divorciadas. A composição etária é diversa, sendo que 49 mulheres estão na faixa etária entre 20 e 30 anos, 34 entre 31 e 40 anos, 29 entre 41 e 50 anos, 26 entre 51 e 60 e 12 têm mais de 60 anos.

\section{UM OLHAR INICIAL SOBRE OS DADOS DO SERTÃO DO APODI}

A análise proposta por este artigo enfoca a influência do trabalho doméstico e de cuidados nas demais informações produzidas pelo diagnóstico. É uma análise inicial e tem como objetivo estabelecer o debate sobre a construção de indicadores não androcêntricos. Consideramos que a observação da viabilidade econômica das atividades produtivas desenvolvidas pelas mulheres requer um olhar anterior para as condições de vida e trabalho destas mulheres na esfera produtiva e reprodutiva. Nesta análise, nos referimos à realidade das 160 mulheres incluídas no projeto de assistência técnica do território Sertão do Apodi/RN, cuja identificação social anunciada durante as entrevistas se refere ao modo de vida camponês. 
Quanto à situação legal de suas terras, 63,75\% das mulheres afirmam que sua família possui terra própria; 2,5\% arrendatárias e 33,75\% apontam outras formas de propriedade da terra, conforme mostra 0 gráfico 1.

Gráfico 1 - Situação Legal da Terra das famílias das mulheres no Sertão do Apodi

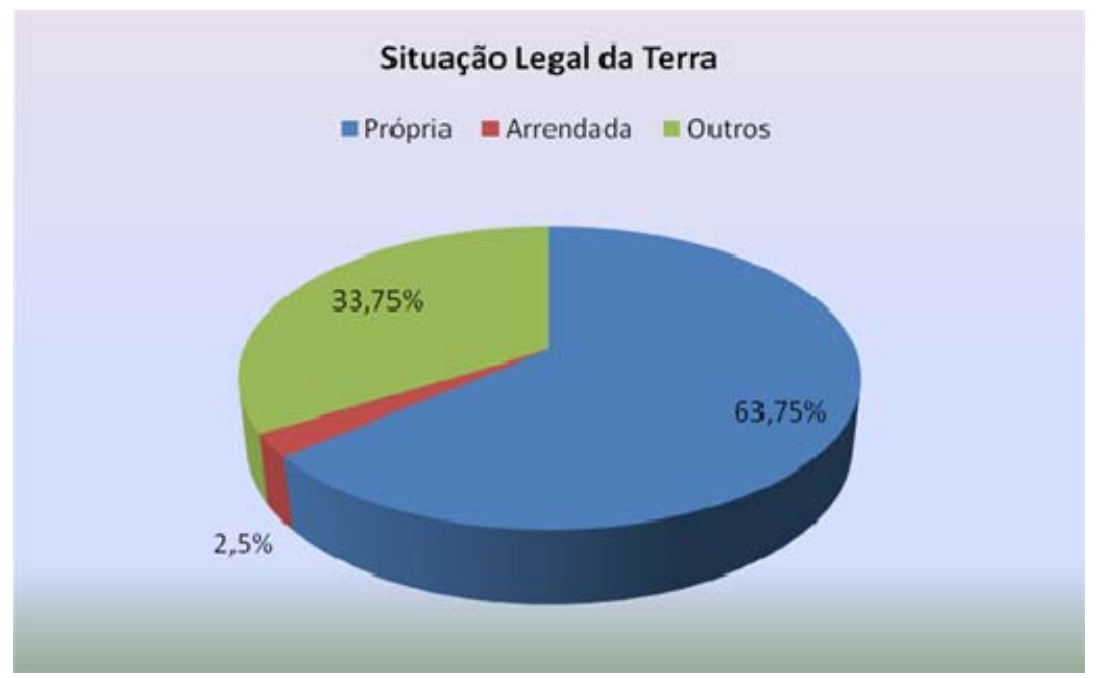

Fonte: Diagnóstico do Território Sertão do Apodi, CF8, 2011.

Apenas 5\% das entrevistadas souberam responder, em hectares, a extensão da propriedade rural familiar relacionada a cada tipo plantação, o que mostra que a proporção de hectares destinados ao plantio de feijão, milho ou mandioca não é um conhecimento comum entre as mulheres.

0 acesso desigual das mulheres à terra é uma realidade em diversas regiões do país. De acordo com a análise do Censo Agropecuário 2006 realizada por Nobre (2012), quando as mulheres são responsáveis pelos estabelecimentos, estes possuem área média inferior a metade da média dos estabelecimentos em que os homens são responsáveis.

Apesar de a terra ser fator fundamental na economia e na vida de camponesas e camponeses, os níveis de utilização das terras por mulheres são desiguais e estão abaixo dos necessários para a conquista de sua autonomia econômica. 0 controle sobre a posse da terra é um fator relevante para a autonomia econômica das mulheres. 0 fato de que apenas 5\% afirmam ter conhecimento sobre o que produz sugere que apenas estas têm controle sobre seus bens, entre o conjunto de mulheres cuja família tem a posse da terra. 
Essa interpretação se apoia na afirmação de Deere (2004) de que o poder de negociação das mulheres na relação conjugal está relacionado com a posição que elas ocupam no interior da família e da comunidade, na relação com os bens que possuem, e se estes estão sob seu controle. Neste caso, deve-se perguntar se a terra pode ser considerada um bem sobre o controle das mulheres, já que os dados indicam que essas não têm conhecimento sobre sua extensão e produção.

Os dados referentes às responsabilidades das mulheres no espaço rural demonstram que todas realizam atividades de diferentes tipos. A grande maioria faz 0 trabalho doméstico conjugado com outra atividade, conforme se verifica no gráfico 2. A construção do gráfico se deu a partir da combinação das atividades realizadas pelas mulheres. As possibilidades de atividades presentes no questionário foram trabalho doméstico, produção de subsistência, criação de pequenos e médios animais, criação de grandes animais, artesanato e outros. Para melhor visualização das categorias de resposta, foram excluídas aquelas combinações cuja frequência foi menor que $5 \mathrm{em}$ números absolutos.

Gráfico 2 - Atividades realizadas pelas mulheres no Território Sertão do Apodi (valores absolutos) ${ }^{5}$

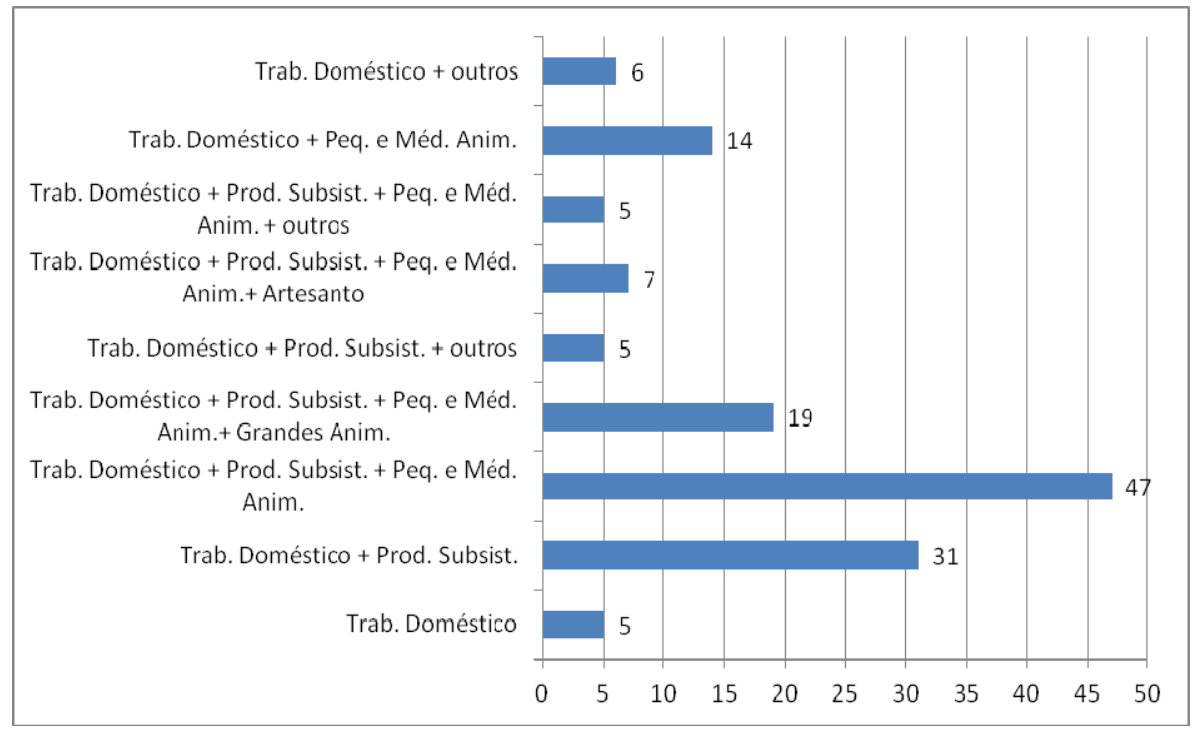

Fonte: Diagnóstico do Território Sertão do Apodi, CF8, 2011.

\footnotetext{
${ }^{5}$ A totalidade dos dados é superior a $100 \%$, considerando que as entrevistadas poderiam marcar mais de uma alternativa, de acordo com o número de atividades que executa.
} 
0 gráfico 2 demonstra que as mulheres acumulam atividades reprodutivas e produtivas. Entre as 160 entrevistadas, apenas 5 realizam somente 0 trabalho doméstico. As demais combinam o trabalho doméstico com uma ou mais atividades, sendo que prevalecem as combinações com a produção para subsistência e/ou criação de pequenos e médios animais.

Estes dados confirmam o argumento de Picchio (2001) e Sen (1990, 2000) de que o trabalho doméstico influencia na quantidade e qualidade do trabalho remunerado e está relacionado com as capacidades adquiridas por cada membro das famílias. Por outro lado, segundo Rodriguez (2010), o trabalho do cuidado também influencia na quantidade de horas disponíveis para o trabalho na produção. Sabe-se que para parte das mulheres, este só é possível com as horas restantes do tempo gasto na responsabilidade com a reprodução. Dito de outra maneira, o trabalho da reprodução está, intrinsecamente, incorporado no espaço da economia, uma vez que, o trabalho produtivo depende da reprodução para manter-se em funcionamento. Um aspecto que se destaca no caso das mulheres rurais se refere à remuneração do trabalho na produção, considerando a prevalência da produção para subsistência entre as atividades produtivas verificadas no diagnostico do Sertão do Apodi.

Para facilitar a análise dos dados, a produção das mulheres foi classificada em três cadeias produtivas: quintal/sequeiro, beneficiamento de polpa de fruta; artesanato. Das 160 mulheres entrevistadas, todas participam da cadeia produtiva denominada no diagnóstico como quintal/sequeiro. Sequeiro é a produção sazonal realizada na região no período chuvoso, especificamente de fevereiro a junho. A predominância produtiva é de milho, feijão, mandioca e batata doce. De acordo com o diagnóstico, 74\% das mulheres participam somente de uma cadeia (quintal/sequeiro); $23 \%$ participam de duas cadeias produtivas, sendo 15\% quintal/sequeiro e beneficiamento de polpa e $8 \%$ Quintal/Sequeiro e artesanato. 3\% das entrevistadas participam das três cadeias produtivas.

A análise dos dados sugere que a adesão da totalidade das mulheres a esta cadeia (quintal/sequeiro) deve-se ao fato de o quintal ser próximo da casa, o que não inviabiliza a conciliação com as responsabilidades domésticas. Além disso, a produção deste espaço é considerada de subsistência, como frutas, plantas medicinais, ovos, galinhas. Conforme a literatura nacional e internacional, a produção de alimentação para o autoconsumo familiar é considerada socialmente como uma extensão das tarefas domésticas. Além disso, a produção dos quintais não tem uma exigência de equipamentos considerados onerosos para a produção, como trator, irrigação, escala de produção entre outros. 
A análise deste gráfico poderia se encerrar na esfera produtiva. No entanto, quando os dados são cruzados com as informações sobre a composição familiar, revelam a influência da esfera reprodutiva na produtiva.

A relação entre a faixa etária dos/as filhos/as e a participação das mulheres em mais de uma cadeia produtiva é demonstrada através da tabela 1 . As mulheres dedicam maior tempo a produtivo quando seus filhos estão em idade maior de dez anos:

Tabela 1 - Relação entre faixa etária dos filhas/os e participação das mulheres em uma ou mais cadeias produtivas

\begin{tabular}{|l|c|c|c|c|}
\hline & $\begin{array}{l}\text { Número de mulheres com } \\
\text { filhas/os de até 10 anos }\end{array}$ & $\begin{array}{l}\text { Número de mulheres com } \\
\text { filhas/os acima de 10 anos }\end{array}$ & $\begin{array}{l}\text { Outras } \\
\text { respostas* }\end{array}$ & Total \\
\hline $\begin{array}{l}\text { Mulheres que participam em } \\
\text { uma cadeia produtiva }\end{array}$ & 68 & 40 & 10 & 118 \\
\hline $\begin{array}{l}\text { Mulheres que participam em } \\
\text { duas cadeias produtivas }\end{array}$ & 16 & 20 & 1 & 37 \\
\hline $\begin{array}{l}\text { Mulheres que participam em } \\
\text { três cadeias produtivas }\end{array}$ & 1 & 4 & 0 & 5 \\
\hline Total & 85 & 64 & 11 & 160 \\
\hline
\end{tabular}

*não tem filhos; tem filhos mas não moram na unidade familiar; não tem filhos mas tem netos, etc. Para esta análise consideramos apenas as duas primeiras colunas

Fonte: Diagnóstico do Território do Sertão do Apodi. CF8, 2011.

0 cruzamento destes dados mostra que as mulheres com filhos cuja faixa etária é inferior a 10 anos têm mais dificuldades em dedicar um maior número de horas em trabalho produtivo, participando apenas em uma cadeia produtiva, em especial naquela próxima da casa e com produção sazonal. Da mesma forma, a participação das mulheres em mais de uma cadeia produtiva é maior entre aquelas que têm filhos em uma faixa etária superior a 10 anos, o que implica menos necessidade de atenção, vigilância e cuidados permanentes. 


\section{CONSIDERAÇÕES FINAIS: INTERDEPENDÊNCIA ENTRE REPRODUÇÃO E PRODUÇÃO, ELABORAÇÃO DE INDICADORES NÃO ANDROCÊNTRICOS E CAMINHOS PARA SEGUIR ESTE DEBATE}

Ao analisar os dados coletados no diagnóstico à luz das reflexões teóricas da economia feminista, destacamos três questões centrais que apontam para a necessidade de aprofundamento na continuidade deste processo.

A produção de informações sobre o trabalho doméstico e de cuidados com filhos permite avançar na compreensão da interdependência entre a produção e a reprodução no meio rural. Destacamos uma particularidade na vida das mulheres rurais. Diferentemente das mulheres trabalhadoras urbanas que têm uma carga horária a cumprir no mundo produtivo, as rurais transitam por várias vezes entre o quintal, 0 roçado e a casa. Assim, o desafio de compreender a interdependência adquire um alcance maior na medida em que, além da questão dos tempos para a produção e a reprodução que se sobrepõem, também o espaço rural não tem uma divisão rígida. As mulheres rurais, sobretudo as que produzem no quintal e sequeiro, estão constantemente nos dois espaços. Assim, um dos aspectos relevantes para o seguimento desta reflexão e futuras pesquisas se refere à potencialidade de se aplicar o conceito da interdependência das esferas na formulação dos questionários. Nesse sentido, uma reflexão importante é se a elaboração do questionário tendo como referência as cadeias produtivas facilita ou dificulta essa compreensão. Isso porque a experiência produtiva das mulheres neste território se relaciona com os princípios agroecológicos, caracterizados pela integração da produção.

Ainda neste sentido, os dados coletados no diagnóstico demonstram a relação entre a participação das mulheres com filhos na produção, mas é necessário apontar a necessidade de ampliar a pesquisa, buscando investigar a influência do conjunto das tarefas envolvidas no trabalho doméstico e de cuidados na esfera da produção. Isso requer compreender que o trabalho de cuidados não se direciona apenas aos dependentes (como crianças, idosos ou doentes), mas também aos adultos.

Outro aspecto decorrente do anterior se refere ao fato de que pesquisas desse tipo podem avançar para mostrar e medir a contribuição econômica deste trabalho, elemento que não foi incorporado devido ao fato de que o escopo da pesquisa era a identificação das demandas das mulheres rurais para orientar a política de ATER no território.

Um terceiro elemento que relaciona a presente pesquisa às reflexões teóricas da economia feminista sobre metodologias e indicadores é a necessidade de articulação de métodos quantitativos e qualitativos. 0 diagnóstico em questão utilizou a pesquisa quantitativa, mas sua elaboração foi precedida de um processo de reflexão do CF8 a partir do trabalho anterior de assessoria aos grupos produtivos de mulheres rurais, o que 
garantiu uma contribuição particular na pesquisa com a introdução da questão sobre 0 acesso à água para medir seu impacto na divisão sexual do trabalho. Verificar este impacto foi importante na medida em que essa era ao mesmo tempo uma preocupação e constatação das mulheres, que se expressaram nos relatos dos processos de assessoria aos grupos.

Assim, as reflexões apresentadas neste artigo procuraram argumentar que o que a produção de estatísticas e indicadores mede ou deixa de medir depende do que é considerado relevante pela orientação teórica na qual se referenciam. Ao relacionar esta reflexão com a formulação e avaliação de políticas públicas para as mulheres, se coloca a necessidade de que as estatísticas e indicadores sejam capazes de dar visibilidade a articulação de dimensões constitutivas da desigualdade de gênero. Neste sentido, a perspectiva feminista apresenta proposições importantes para se avançar na coleta e interpretação dos dados. Aponta a necessidade de que se estabeleça como objetivo a compreensão da esfera da reprodução e sua relação com a esfera da produção. Faz-se necessário visibilizar a sobrecarga de trabalho das mulheres e as consequências da conciliação entre produção e reprodução. Ao mesmo tempo, também é necessário verificar se há alterações nas configurações da divisão sexual do trabalho, ou seja, medir a participação dos homens na esfera da reprodução. Além disso, esta reflexão aponta para a superação da dicotomia e antagonismo entre as diferentes esferas da produção e reprodução, compreendendo sua interdependência. Esta é uma dimensão importante para que a conquista de autonomia econômica das mulheres esteja relacionada com a construção de relações de igualdade.

Aliados ao processo de organização das mulheres no território, esses elementos contribuem para a formulação de políticas públicas para as mulheres voltadas à promoção de igualdade e autonomia, em especial no que se refere às mulheres rurais. As creches, lavanderias e restaurantes coletivos respondem a necessidade de algumas realidades rurais como 0 caso dos assentamentos rurais da reforma agrária. No entanto, ainda persiste o desafio de elaboração de políticas públicas capazes de responder à socialização do trabalho doméstico e do cuidado entre Estado, homens e mulheres nas diferentes realidades rurais brasileiras. Desta forma, a produção de estatísticas e indicadores capazes de demonstrar a magnitude e a complexidade das dinâmicas da desigualdade, especialmente no que se refere ao tempo e ao trabalho, é uma estratégia que contribui para que as políticas sejam efetivas em seu objetivo de garantir o bem estar e qualidade de vida de todos os membros da comunidade. 


\section{REFERÊNCIAS}

ALVES, Maria de Fátima Paz. Gênero e crédito no oeste Potiguar: uma experiência de inclusão e articulação. Brasília: NEAD/ MDA e Secretaria de Agricultura Familiar, 2007

BRUSCHINI, Cristina. Trabalho doméstico: inatividade econômica ou trabalho não remunerado? Revista Brasileira de Estudos Populacionais, São Paulo, v. 23, n. 2, jul./dez. 2006.

BUTTO, Andrea. Estatísticas rurais e a economia feminista: um olhar sobre o trabalho das mulheres. Brasília: Ministério do Desenvolvimento Agrário, 2009.

BUTTO, Andrea; DANTAS, Isolda; HORA, Karla (Org.). As mulheres nas estatísticas agropecuárias: experiências em países do Sul. Brasília: Ministério do Desenvolvimento Agrário, 2012.

CARRASCO, Cristina (Org.). Estatísticas sob suspeita: proposta de novos indicadores com base na experiência das mulheres. São Paulo: SOF, 2012.

CARRASCO, Cristina (Org.). Mujeres y economía. Barcelona: Icaria, 1999.

CARRASCO, Cristina. El tiempo y el trabajo desde la experiencia femenina. In: CARRASCO, Cristina. La economía invisible y las desigualdades de género. Barcelona: Organización Panamericana de Salud, 2008.

CARRASCO, Cristina. Sustentabilidade da vida humana: um assunto de mulheres? In: FARIA, Nalu; NOBRE, Miriam (Org.). A produção do viver: ensaios de economia feminista. São Paulo: SOF, 2003. p.11-49.

CARRASCO, Cristina. La economía feminista: una apuesta por otra economía. Barcelona, 2006. Disponível em <http://www.seminariovirtual.com.ar/seminario20102/documentos/Carrasco-recomendadoAlmaEspino.pdf>

DEDECCA, Cláudio. Tempo, trabalho e gênero. In: COSTA, Ana A. et al. (Org.). Reconfiguração das relações de gênero no trabalho. São Paulo: CUT, 2004.

DEERE, Carmen Diana. Os direitos da mulher à terra e os movimentos sociais rurais na reforma agrária brasileira. Revista Estudos Feministas, Florianópolis, v. 12, n. 1, p. 175-204, jan./abr. 2004.

RODRIGUEZ, Corina. Análisis económico para la equidad: los aportes de la economía feminista. Consejo Nacional de Investigaciones Científicas y Técnicas y Centro Interdisciplinario para el Estudio de Políticas Públicas. SaberEs, n. 2, p.3-22, 2010. Sección Autora Invitada

FERBER, Marianne; NELSON, Julie. Mas allá del hombre económico. Madrid: Ediciones Cátedra, 2004. 
FOLBRE, Nancy. Medir los cuidados: género, empoderamiento y la economía de los cuidados. In: BORDERÍAS, Cristina; CARRASCO, Cristina, TORNS, Teresa (Org.). El trabajo de cuidados: história, teoría y políticas. Madrid: Catarata, 2011. Cap. 8, p. 278304.

HIRATA, Helena; GUIMARÃES, Nadya (Org.). Cuidado e cuidadoras: as várias faces do trabalho do Care. São Paulo: Atlas, 2012.

KERGOAT, Daniele. Divisão sexual do trabalho. In: HIRATA, Helena et al. Dicionário crítico do feminismo. São Paulo: Ed. UNESP, 2009.

NOBRE, Miriam. Censo Agropecuário 2006 - Brasil: uma análise de gênero. In: BUTT0, Andrea; DANTAS, Isolda; HORA, Karla (Orgs). As mulheres nas estatísticas agropecuárias: experiências em países do Sul. Brasília: Ministério do Desenvolvimento Agrário, 2012.

NOBRE, Miriam. Introdução à economia feminista. In: FARIA, Nalu; NOBRE, Miriam (Org.). Economia feminista. São Paulo: SOF, 2002. Coleção Cadernos Sempreviva

PÉREZ, Amaia Orozco. Perspectivas feministas en torno a la economía: el caso de los cuidados. Madrid: Consejo Económico y Social, 2006.

PICCHIO, Antonella. Un enfoque macroecómico ‘ampliado' de las condiciones de vida. In: CARRASCO, Cristina (Org.). Tiempos, trabajos y gênero. Barcelona: Publicacions Universitat de Barcelona, 2001. p. 4-28.

RODRIGUEZ, Corina. La cuestión del cuidado: ¿El eslabón perdido del análisis económico? Revista CEPAL, Santiago de Chile, n. 106, p. 23-36, abr. 2012.

SEN, Amartya. Desenvolvimento como liberdade. Tradução de Laura Teixeira Mota. 6. ed. São Paulo: Companhia das Letras, 2000.

SEN, Amartya. Gender and cooperative conflicts. In: TINKER, Irene (Org.). Persistent inequalities New York: Oxford University Press, 1990.

TEIXEIRA, Marilane. Sistema de indicadores de gênero: instrumento para conhecer e reconhecer a experiência das mulheres. In: CARRASC0, Cristina. Estatísticas sob suspeita: proposta de novos indicadores com base na experiência das mulheres. São Paulo: SOF, 2012. 